Artículos 



\title{
Pensamiento crítico versus razón arrogante
}

\author{
Carlos Pereda
}

$\mathrm{T}$

al vez uno de los mayores combates que debe dar la filosofía o (si se favorecen palabras más ligeras, menos sobrecargadas por la tradición) el pensamiento crítico, que incluso especifica cuáles son y deben ser, al menos, varias de sus tareas, se juega en las diversas luchas en contra de la corrosiva intervención, además muy frecuente, de la razón arrogante.

Los objetos con que opera tal razón son casi cualquier cosa, en la teoría y en la práctica. Este peculiar mecanismo, día a día recorre los haceres. Así, por ejemplo, contamina esa ruta que va de las identificaciones más inocuas -"este barrio es mejor que el de ustedes porque aquí sabemos hacer chilaquiles y usamos sombreros grandotes y, por eso, ustedes no valen nada" - hasta los entusiasmos más peligrosos, esos que generan los nacionalismos más excluyentes, más infames, y su consecuencia, las guerras de exterminio.

Anoto otros ejemplos muy diferentes, pero en la misma dirección: la ininterrumpida división del mundo en centroperiferia, oposición con la que, a su vez, se articula cada región -país, ciudad, barrio...-, no ha hecho más que fortalecer la razón arrogante de los centros respecto de sus imaginadas y, no pocas veces, programadas periferias. Por eso, la expresión "razón arrogante", ¿no se vuelve a menudo equivalente de la expresión "razón colonizadora"? De nuevo, tengamos en cuenta la regla:

\section{¡Ten cuidado con las palabras!}

No es arduo descubrir sus dos advertencias. Hay que cuidar a las palabras pues con ellas atravesamos la vida, nos entendemos y hasta, en parte al menos, nos construimos y construimos el mundo. Sin embargo, por eso mismo, debemos también cuidarnos de ellas, ya que con facilidad marean y nos llevan 
por el mal camino. Cuando se sospecha que una operación frecuente de la razón arrogante consiste en "conquistar", usamos ese enérgico verbo con los significados de apoderarse, de hacernos dueño de algo, de dominar por la fuerza. Pero ¿de qué maneras conquista la razón arrogante? Cuando su argumentar parcialísimo procura apropiarse a toda costa de "lo otro", sea lo que fuere lo otro. Así, con entusiasmo se razona el apoderarnos de un territorio para usarlo a nuestro arbitrio, o el tomar posesión de una tradición cultural a la que traducimos, forzándola en nuestros conceptos, sin realmente querer aprender nada de ella.

Otros ejemplos: razonando de esta manera, el trato con grupos enteros de personas -mujeres, indígenas, emigrantes, personas "de color" (el "blanco", ¿no es un color?), pobres, gitanos, judíos, gays, chicanos...- ha sufrido sistemáticamente de diversas conquistas.

También en el interior de cada animal humano, un aspecto de él, tiende a conquistar el resto. En no pocas ocasiones se procura que la razón conquiste los deseos y los sentimientos, y que -como han aconsejado, no sin amargura, muchos moralistas- establezca su "dominio" sobre esos desordenados rebeldes. Tampoco ha faltado la propuesta inversa.

Hasta con ideales políticos irreductibles como la libertad y la igualdad se procura que el uno se adueñe del otro, sin quienes los defienden respeten sus contrapuestas exigencias, las necesidades muy diferentes que expresan cada uno de ellos.

Pero... basta ya con enlistar ejemplos al azar. Si se busca pensar críticamente la alta velocidad, las ansias por recorrer a vuelo de pájaro una totalidad, son el primer obstáculo a vencer. En este sentido, no olvidemos la sabia cautela: no pocas veces, menos es más. En efecto, dar dos o tres saltos en el pensamiento y demorarse en uno o dos ejemplos, o más bien, en uno o dos detalles de uno o dos ejemplos, con frecuencia resulta más instructivo para abarcar el todo de un asunto, que los copiosos inventarios y las precipitadas visiones de conjunto.

Vayamos, pues, con calma. Por lo pronto, ¿a qué se hace referencia cuando se usa esa expresión anómala, "razón arrogante"? ¿Acaso el razonar puede ser arrogante? ¿De qué vicio o vicios se trata?

Cuando nos aproximamos a este tipo de razón, encontramos una doble desmesura. Sobra el ensalzarse en la concepción que se posee de sí; y como derivándose de éste, prolifera la desmedida en lo que se considera que debe valer para todos. Como contraparte, no es menos desproporcionada la degradación por el resto, por lo que no cae bajo el ámbito de dicha preeminencia.

Retomemos el problema del nacionalismo. Vivimos en medio de diversas filiaciones. Como enseñó Ortega: "yo soy yo y mi circunstancia, y si no la salvo a ella, no me salvo yo". De caso en caso cultivo mis filiaciones a una o 
varias circunstancias: a mi familia, a mis amigos, a mi lugar de trabajo, a la región en que nací, a la lengua que hablo, a ciertos ideales políticos, a las tradiciones que, en parte, me constituyen... Algunas veces, la situación es tal -ciertas urgencias nos presionan tanto- que nos preocupamos de manera preponderante con una filiación. Sin embargo, cuando se busca que esta filiación conquiste, en cualquier situación, el resto de las otras, que esta filiación agote lo que importa para una persona y se desprecie el resto de las posibles filiaciones, nos encontramos ante un alarmante concepto de desmesura de la razón arrogante, por ejemplo, el nacionalismo.

En general, con una autoafirmación y un desprecio desmesurados como éstos se arma un mecanismo de enorme efectividad. Por eso, quien argumenta a partir de la razón arrogante considerará que el cuidadoso causar mengua o descrédito opera ya como una base de la propia nobleza. Para este razonar, la capacidad de negación conlleva en sí suficientes razones para respaldarse. De ahí que su autoafirmación se apoye casi en exclusiva en la desestima general de "todo lo otro", por supuesto, incluyendo el desprecio de quienes no piensan como yo.

Para volver al ejemplo del nacionalismo, no se olvide que el nacionalista apoya una filiación absoluta a su patria en el quitar valor a las otras patrias y, lo que es tal vez más peligroso, a sus otras filiaciones, hasta a las más íntimas.

Por articularse como parte de un aceitado mecanismo, en la razón arrogante tanto un exceso de autoafirmación como de desprecio se vuelven sistemáticos. Puestos en marcha, un excederse apoya al otro: ambas desmesuras se generan recíprocamente.

Así, en el nacionalismo, cuanto más nos obsesionamos con la propia nación, más envilecemos los otros valores, hasta llegar a desdeñar la propia vida.

Dejo ya de ocuparme con el nacionalismo como un ejemplo del funcionamiento de la razón arrogante - que lamentablemente nos visita demasiado- y paso a examinar una consecuencia muy general de este tipo de argumentar. Consiste en separar un proceso de dar razones del resto de los otros procesos de dar razones, e inmunizarlo. De esta manera, se discute levantando murallas. Poco a poco, ninguna pregunta, perplejidad, matiz, duda, objeción, ironía, sarcasmo, ataque... puede interpelar ya las posiciones que defiende una razón arrogante plena de sí. Por eso, a partir de cierto momento, este razonar continúa, a solas, intentando conquistar por doquier. La razón arrogante no conoce otra técnica de razonar que ese laberinto de espejos, el vértigo argumental.

Como ya advertí, la razón arrogante lo inunda todo, incluyendo los problemas más generales y abstrusos. Cuidado..., porque aquí daré un primer salto y me detendré, precisamente, en una de esas tercas dificultades. En contra de lo que se suele fantasear, los problemas metafísicos no cesan de ramifi- 
carse, y llegan a iluminar ampliamente, o a distorsionar y corromper, hasta las prácticas más puntuales e inmediatas.

Dentro del ámbito de la metafísica, tal vez infinito, en esta reflexión me aproximaré sólo a varios efectos de la razón arrogante en la oposición que se establece entre dos tradiciones de pensamiento: aquellas que defienden la capacidad de actuar con autonomía y las que las desafían, poniendo en duda esa capacidad.

$\mathrm{O}$, si se prefiere, plantear la batalla tomando en cuenta el desdoblamiento de la conciencia que se articula en la estructura gramatical: después de esbozar el choque entre la tradición de la confianza en el poder de decidir en primera persona, y la tradición que amenaza esta ambición desde diversas construcciones de la tercera persona, examino cómo la razón arrogante las arruina a ambas.

\section{II}

En la tradición de pensamiento que parte de la confianza en las capacidades de la primera persona se concibe a los animales humanos como agentes genuinos: con poderes eficaces. En tanto tales, siguiendo sus razones - la trama de sus creencias, deseos...-, los agentes hacen, en cierta medida, al mundo y en ese hacer, se hacen a sí mismos. A partir de estas premisas, se considera que las instituciones y las reglas de convivencia social resultan de esa actividad constructora: de esta capacidad humana tan propia que sería la libertad.

Esta convicción, la de la libertad, con su doble cara, la autonomía y la responsabilidad, pretende recoger la experiencia más inmediata que cualquier animal humano, en tanto primera persona, realiza de su hacer. Si deseo tomar un vaso de agua, en condiciones normales, lleno con agua un vaso y me la tomo. Si se me pregunta por qué lo he hecho tal vez responda: "yo decidí hacerlo, tenía sed", o "yo creí que debía hacerlo, pensando en mi salud", o "yo quise hacerlo calculando que en las próximas horas me sería difícil tomar agua”.

La acción de tomar un vaso de agua es elemental. No obstante, cualquier acción que imaginemos que se pueda realizar a solas o con otros -visitar a un amigo, cometer un crimen, casarse, hacer un fraude, inventar un remedio decisivo, mentir, rezar, pintar un cuadro magnífico, robar, unirse a un gran partido político, traicionar, bailar, comenzar una revolución...-, ante preguntas del tipo “¿por qué lo has hecho?”, “¿por qué lo han hecho?” podría recibir -entre otras- ese tipo de respuestas. (Claro, también se contesta con disculpas, con excusas, con explicaciones... que buscan mitigar la agencia, y la responsabilidad.) Esas respuestas que aluden a un animal humano que razona y es, para usar una metáfora conocida, "dueño" de sus acciones, hacen refe- 
rencia al concepto de autonomía. (Por supuesto, la palabra "autonomía" no es sinónimo de "autarquía". Escuchar a los otros, entregarse a ellos, incluso por entero como a veces lo hacemos en el amor, en la amistad, y en algunas formas de la solidaridad, o de la piedad, implica también autonomía con un alto grado de receptividad.)

Empleando la terminología a que a veces se ha echado mano en esta tradición se afirmará que el animal humano "causa" sus acciones. Porque a diferencia de los otros animales, el animal humano posee - para usar la oscura, aunque sugestiva expresión de Kant en la tercera antinomia de la Crítica de la razón pura- una "causalidad por libertad": dispone de la aptitud de generar sus propias prácticas y teorías.

Por el contrario, para las tradiciones que amenazan la capacidad humana de decidir y actuar libremente, este lenguaje - "el animal humano en tanto agente", "la primera persona que es dueña de sus acciones", "autonomía", "causalidad por libertad"...- no conforma más que fragmentos de un cuento fantástico (¿e infantil?). En el mejor de los casos, sólo se hace referencia a narraciones de series de apariencias de la primera persona, y nada más. Debemos redirigir la atención. Debemos abandonar esa ciencia-ficción que ha sido la metafísica y sus chirimbolos y neblinas, y confrontar la dura realidad desde el punto de vista de una tercera persona progresivamente imparcial.

Quien busque objetividad necesita desechar, entonces, aquello que se le presenta más de inmediato a la mente, a la "experiencia vivida" -valga el pleonasmo- de la primera persona. En particular, hay que socavar esa vana confianza que los animales humanos poseen acerca de su libertad teniendo en cuenta más datos, y en varias direcciones. Pero, ¿cuáles?

Entre otros, se han ofrecido cuatro tipos de datos a partir de diversas construcciones de la tercera persona. Con base en ellos, podemos reconstruir una tradición de pensamiento con cuatro versiones que recogen algunas de las creencias que amenazan la existencia genuina de las acciones -que se pretenden diferentes de manera radical de los meros sucesos naturales- y, en consecuencia, de la libertad -que se distinguiría, también con radicalidad, del operar de ciertos dispositivos por completo fuera del control de cualquier animal humano.

La primera versión de estas amenazas es teológica. El Destino, los dioses o Dios, han ya predeterminado nuestros haceres, con independencia de lo que se crea o decida. Son los dioses, o Dios, quienes tejen y destejen la Historia, y por supuesto las historias, cada historia. Opera la Gracia. La Providencia "actúa" donde quiere y no se sabe "ni de donde viene ni a donde va".

La segunda versión parte de las premisas "todo estado y suceso tienen una causa" y "en toda relación causal, la causa es suficiente para que se dé el efecto". A partir de estas premisas se saca la siguiente conclusión: como es 
causalmente necesario todo estado y suceso que se da, por lo tanto, el futuro se encuentra tan fijo como el pasado. Esta versión -que aparece en muchas civilizaciones, y en Grecia de modo muy elaborado en los estoicos- ha cobrado progresiva popularidad al convertirse en un fragmento de la metafísica de las ciencias naturales que identifica cualquier acción con un suceso relacionado con otros sucesos, y nada más.

Obsérvese que para esta segunda versión de la amenaza, y en contra de su punto de partida, resulta indiferente el tipo de relación entre los sucesos. Esto es, no importa que se considere que el universo es determinista (como lo plantea el estoicismo o Kant en su tercera antinomia) o indeterminista (como lo propuso la nueva física, en particular, la interpretación de Heisenberg). Tanto las acciones descritas como sucesos con causas en un universo determinista, como las acciones sin causa en un universo azaroso, no dejan lugar para que un animal, él mismo, en su libertad actúe como decide actuar. Tanto el determinismo como el indeterminismo amenazan la posibilidad de la acción libre tal como la describe la tradición de la confianza en la capacidad humana de decidir: la acción como producto de la autonomía de un agente con responsabilidad por lo que hace.

Según esta metafísica, a partir de ciencias como la física y la química, el lenguaje de las acciones y de la libertad sería análogo -en el mejor de los casos- al lenguaje de los colores. Nos encontraríamos ante un lenguaje de cualidades secundarias que desaparecen -como ilusiones proyectadas por los órganos de cierta especie- en la versión de las cualidades primarias del mundo que reconstruyen la física y la química.

La tercera fuente que amenaza la agencia la provee la biología moderna o, si se prefiere, de nuevo, cierta metafísica que se inspira en ella. ¿No nacemos, acaso, no sólo con un sexo, un color de piel, de ojos y de cabellos, sino también con cierto ADN? En el mapa genético, ¿no se encuentran ya, en alguna medida, predeterminados los dispositivos de la inteligencia y de los dones, hasta las enfermedades e incluso ciertas posibilidades de vida?

En estas dos últimas versiones de la tradición de la amenaza, en los datos de las ciencias naturales que se suelen introducir para formular los ataques a nuestras confianzas, se tiende a cambiar de tipo de conceptos. Se pasa del lenguaje práctico en el que se habla de acciones y responsabilidades, a un lenguaje teórico, físico-químico o biológico. En estos vocabularios se usan palabras ajenas a la práctica - por supuesto, ello no conforma ninguna razón contra ellos- como "átomos", "moléculas" y "leyes físicas", por un lado, y "ADN", "genoma humano" y "leyes genéticas", por otro.

No obstante, existe cierta diferencia, por lo menos gradual, entre ambas amenazas. La primera - la amenaza del determinista o del indeterminista- produce un efecto, por llamarlo de algún modo, "abstracto"; pocas veces -salvo 
en el fatalismo estoico y en tradiciones similares- posee consecuencias directas en las prácticas humanas. (Cuando las hay, pueden ser muy variadas: en el estoicismo nos encontramos con una actitud liberadora de las ansiedades y temores de cada día y, en último término, de la muerte.) No así las amenazas provenientes de la biología. Saber que a partir de una determinada fecha sufriremos de una terrible enfermedad -digamos, Alzheimer- tenderá a cambiar cómo vivimos la espera hasta padecer dicha enfermedad.

En la cuarta versión de la tradición de la amenaza no se realizan cambios radicales de perspectiva respecto de la praxis o de prolongaciones y elaboraciones suyas. Pero como en el caso de la biología, la amenaza también posee consecuencias directas respecto de las más diversas prácticas. En este tipo de amenazas, no se procura minar la libertad del agente y sus acciones redescribiéndolas con un lenguaje rigurosamente paralelo e inaccesible a su experiencia inmediata -teológico o perteneciente a las ciencias naturales-, sino de defender que lo que hacen los agentes no es más que una consecuencia de lo que les ha pasado y les sigue pasando. ¿Y qué les ha pasado y les sigue pasando? Preguntando con más precisión: ¿qué, dentro de lo que les ha pasado y les sigue pasando a los animales humanos, "determina" su potencial de deseos, creencias, emociones, esperanzas... operando en tanto razones?

Los animales humanos poseen una larga y a menudo áspera niñez en que minuciosamente dependen de las generaciones anteriores. A veces se considera que esa vulnerabilidad es total; como sugiere el dictum clásico: infancia es destino. Además, se insiste en que esa vulnerabilidad es, ante todo, afectiva. Por eso, cuando el animal humano adulto razona y actúa, sus razones y acciones en cierta medida repiten varias de las escenas más afectivamente cargadas de los primeros años de vida. (Estas escenas, para ciertas teorías, se retienen en el "inconsciente".) Por eso, quizá haya tan poco espacio para escapar al destino de la infancia, como lo hay para quebrar el Destino de los dioses.

No obstante, incluso si quedase algún margen de acción, no podemos ignorar que los animales humanos hacen su vida trabajando dentro de estructuras sociales, específicamente económicas, que nadie en particular ha creado o siquiera regula por completo. Son esas estructuras del mercado las que "determinan" cómo actúa y hasta qué piensa y desea el acosado animal humano, las que lo llevan al éxito o a la ruina. (Más bien, a lo que esas ficciones deslumbrantes de los animales humanos, "la libertad", "las personas", "la autonomía", "la responsabilidad"..., denomina con palabras igualmente sonoras como "éxito", "ruina".)

¿Cómo pensar críticamente estas amenazas a la confianza en nosotros mismos? Ante todo, quiero hacer dos observaciones. En primer lugar, sin duda, he estado simplificando y mucho; pero creo que he estado simplificando en 
la dirección correcta. En segundo lugar, en relación con cada una de las versiones que enumeré como amenazadoras de la libertad, se pueden vincular movimientos y nombres venerables, y también harto divergentes, cuyo estudio complicaría y, especialmente, refinaría, el grueso esquema expuesto de esta tradición de pensamiento. Entre otros movimientos y nombres, podemos recordar la tragedia griega, el estoicismo, san Agustín y el conflicto entre la predestinación y el libre albedrío, Darwin y la teoría de la evolución, Freud y los caminos del inconsciente, Marx y la dinámica propia de las diversas etapas del desarrollo social, Foucault y las estructuras del poder, la sociobiología, las neurociencias y sus propuestas reduccionistas...; además de las muchas maneras, no pocas veces en direcciones opuestas, en que se ha trabajado a partir de esas temáticas, o análogas. Sin embargo, la verdad o el valor de un pensamiento no depende de quienes lo hayan pensado y defendido. ¿Cómo evaluar pues, en general, estas amenazas?

Para no dejarnos intimidar por una moral del miedo, tal vez un buen consejo consista en tratar de convertir, en cualquier caso, las amenazas en desafíos (¿la estrategia estoica?). Sin embargo, frente a la inquietante pregunta acerca de cómo evaluar estas amenazas, casi inevitablemente reaparece, para enredar más la situación, la razón arrogante. Mi conjetura: tanto la confianza en nuestra capacidad de decidir, como las lecciones de sus diversas amenazas o desafíos - por otra parte, no olvidemos, construidos a partir de esa capacidad- se inutilizan cuando se sucumbe a este tipo de razonar. Atendamos.

Siguiendo el punto de vista de la primera persona en tiempo presente, algunos argumentos respaldan el concepto de autonomía observando que lo que se considera en las actividades de cada día como "mundo humano", entre otros, el "mundo moral" y el "mundo político", desaparecerían sin ese raro presupuesto, la libertad. Muchos señalan que ningún esfuerzo o proyecto valdría la pena; más todavía, ni siquiera tendría sentido si las acciones estuviesen por completo fuera de nuestro control. En un mundo constituido puramente por sucesos - por lo tanto, sin acciones genuinas- todo lo que hay carecería de valor y se reduciría a series de sucesos que suceden de acuerdo a cierta causa que, a su vez..., y así sucesivamente. Estas comprobaciones, sin embargo, no deben hacer olvidar los otros argumentos: aquellos que desafian la confianza en la libertad con lenguajes teológicos, o a partir de datos de las ciencias naturales o sociales.

Lamentablemente, con demasiada rapidez se sucumbe en alguna falta de mesura: o se reafirma sin más la confianza en la libertad de decidir y de actuar y, así, con razón arrogante se procura desdeñar sus desafíos. O viceversa.

Cada uno de estos excesos sistemáticos, por un lado, en la confianza en nosotros mismos en tanto agentes, o, por otro, en sus desafíos, suele regirse por el mecanismo de la razón arrogante que consiste en respaldar una 
autoafirmación desaforada casi en exclusiva en el desprecio o mera negación de la posición opuesta.

En la tradición de la confianza, con razón arrogante se reitera el edificante murmullo "soy libre, soy libre, soy libre..."; a la vez, se desestiman como sin sentido los desafíos por respaldarse en datos que no se pueden obtener en la experiencia inmediata de los agentes en primera persona, o datos que pertenecen al "mundo humano". Esta última afirmación presupone que la experiencia de los agentes, que el "mundo humano", se encuentra demarcado y hasta cerrado. De esta manera, los experimentos y otras herramientas científicas que se diseñan desde los puntos de vista de la tercera persona no se rigen por la lógica de las continuidades y rupturas en relación con esa experiencia.

En dirección opuesta, pero con razón arrogante no menor, con facilidad se convierten las dudas teológicas, metafísicas, biológicas, psicológicas, sociales, económicas... que introducen los desafíos sobre la autonomía humana en firmes apoyos para la total eliminación de esa autonomía. Entonces, tal vez ya "todo" no sólo no es como parece, sino que "todo", se vuelve con la mayor certeza - ¿pero de dónde proviene esa fiera certeza?- en lo opuesto de lo que parece.

Así, tanto a partir de las tradiciones de la confianza en la agencia humana como de aquellas que la amenazan, o más bien, la desafían, se considera que se dispone de la versión completa del proceso de dar razones: del patrón conceptual únicamente válido que se debe adoptar. En cada caso se ignora que tal vez estamos ante aspectos de la existencia humana -confiar en la capacidad de decidir, ser desafiados en las teorías o en las prácticas, asumir puntos de vista de la primera y de la tercera persona...- que, entre otros, hay que tener en cuenta para comprender al mundo, a nuestras sociedades y a nosotros mismos como parte de todo ello.

Soy terco. No creo que podremos en algún momento eliminar esta perplejidad del proceso de dar razones: esta tensión entre la experiencia inmediata de la libertad desde el punto de vista de la primera persona, del agente, y sus muchos y diversos desafíos desde el punto de vista de la tercera persona, del observador. No lo lograremos incluso si se toma distancia, grande o pequeña, de conceptos tan ambiciosos como los usos, propios de la tradición kantiana, de palabras como "libertad", "autonomía", "responsabilidad"... y nos limitamos a los significados modestísimos de esas palabras en los haceres de cada día.

Por eso, si en algún recodo del camino, la razón arrogante no convierte la arraigada tendencia humana a la producción de sectas, en definitiva ceguera, nuestra capacidad de juicio tendrá que vivir tironeada de este modo para siempre. Ojalá. Ojalá nos continúe acompañando esta muy virtuosa inquietud. Porque de seguro ésta es la manera en que somos. 
Doy un segundo salto. Esta vez pasaré de los vastos y enredados problemas metafísicos anteriores a experiencias muy comunes, casi insignificantes, de la vida cotidiana, pero que plantean dificultades no menos enredadas y ni siquiera independientes de aquellos problemas generales. Sin embargo, de manera explícita o implícita, ¿no sucede esto con frecuencia? El pensamiento crítico, ¿acaso no implica desarrollar procesos de dar razones deteniéndose frente a problemas de diferente nivel de abstracción e importancia?

Cuento una de esas experiencias individualísimas: son las diez de la noche y tengo hambre. Me acerco al refrigerador y lo abro. Sé que debo cuidar mi colesterol y, por lo tanto, he decidido no comer más queso. Hace días lo decidí. No obstante, cada noche, pese a mi decisión, vuelvo a sucumbir en la tentación y, casi sin darme cuenta, corto un trozo de queso y me lo como.

Desde el punto de vista de la primera persona, el contenido de mi decisión de no comer queso me compromete a no comer queso. En tanto agente, mi decisión no ofrece un dato empírico más para predecir mis acciones futuras, sino que conforma una resolución de la que soy responsable. Expresando esta experiencia en el lenguaje de la tradición de la confianza en la capacidad humana de decidir, puede indicarse: si yo resuelvo no comer más queso para cuidar mi colesterol, no estoy descubriendo nada, ni en mí mismo, ni en el mundo, sino que me invento, construyo mi futuro, ejerzo mi libertad.

Por el contrario, desde el punto de vista de la tercera persona, de un observador externo o de yo mismo en tanto observador de mi propia conducta, tomo de inmediato distancia de ese lenguaje - ¿demasiado optimista y altisonante? - y atenderé mi decisión como un hecho psicológico más, junto a los otros hechos empíricos. Así, conociendo mi historia personal, y otras historias similares, la decisión de no comer queso aparece como un dato poco confiable para predecir mi comportamiento presente, y futuro. Pues, si en las noches pasadas he quebrado mi decisión, ¿por qué no lo habría de hacer en el presente, y en el futuro?

La relación de un animal humano con su decisión es, pues, distinta si se adopta el punto de vista de la primera o de la tercera persona. Es una lástima que en ambos puntos de vista, una y otra vez, estos animales vuelvan a ser presa de la razón arrogante y olviden que necesariamente son, a la vez, primera y tercera persona (entre otras perspectivas).

No se puede pasar por alto, sin embargo, cierta gradual asimetría entre ambos puntos de vista. Espontáneamente adoptamos el punto de vista de la primera persona. En cambio, aunque el punto de vista de la tercera persona está también necesariamente presente en cualquier animal humano -no podría haber conciencia reflexiva sin él-, el grado en que lo esté, depende de 
cada individuo y hasta de cada tradición. Por ejemplo, la tradición de las ciencias naturales ha sido una eficacísima escuela para entrenar y, en consecuencia, desarrollar el punto de vista de la tercera persona.

En cualquier caso, cuando un animal humano adopta el punto de vista de la primera persona, se vuelve presa de la razón arrogante si, desatendiendo las informaciones empíricas del punto de vista de la tercera persona, restringe o elimina de su consideración los reportes acerca de sus éxitos y fracasos empíricos en el pasado, respecto del plan de vida que adoptó. El previsor Ulises es, en este sentido, ejemplar: conoce sus debilidades y, por eso, se hace atar; razonablemente no confía en el poder de su agencia en primera persona ante la situación turbulenta que se le avecina. Pero, no por ello, su racionalidad es "imperfecta", como a veces se la califica. Por el contrario, en tanto agente racional, Ulises no olvida que es un cuerpo con necesidades productos de la naturaleza y de la historia. Tampoco niega el espesor de su mente, igualmente producto de la naturaleza y de la historia.

Algo similar puede decirse del amplio repertorio de astucias del tipo "Ulises" que adoptamos en la vida cotidiana. Por ejemplo, estrategias mínimas como: en medio de una comida levantarse a lavarse los dientes para no continuar comiendo; o no comprar cigarrillos, pues aunque no se ha podido dejar de fumar, se deja al azar si alguien dispone de ellos o no. Sin embargo, a diferencia de estas astucias y, en general, de la gente con cierto grado de lucidez que, por eso, cultiva al pensamiento modesto, cuando la primera persona cae presa de la razón arrogante provoca una confianza desmesurada en sí. Ésta, a su vez, tiene como resultado una desautorización y, pronto, una huida de la realidad empírica, o arrogancia normativa (casi diría: o borrachera normativa). El animal humano cree que, en tanto agente, puede olvidarse de la tercera persona y sus reportes empíricos acerca de su naturaleza y de su historia, e inventarse a sí mismo desde cero. De ahí que crea -y aquí, sí, nos encontramos ante un caso de racionalidad muy, muy "imperfecta" - que su decisión le pertenece como si no fuese un cuerpo, ni también una historia construyéndose en medio de otras historias.

Sobre todo algunos límites que impone el propio cuerpo no son, literalmente, posibles de franquear. La edad, los grados de salud y de enfermedad, los dones físicos, el pasado entrenamiento... demarcan a veces incluso de modo muy nítido, al menos, el repertorio de mis acciones imposibles. Es claro: por más que admire surfear, y decida hacerlo, a partir de cierta edad ya no podré comenzar a practicar más ese deporte.

A la inversa, cuando se asume el punto de vista de la tercera persona, esa posición de observador se convierte en presa de la razón arrogante si busca eliminar al animal humano en tanto agente responsable capaz de cumplir con sus proyectos y compromisos. Un síntoma de esta situación es, por ejemplo, 
cuando un paciente le señala a su médico: "Usted sabe, de la misma manera que yo, cuáles son mis probabilidades de no romper cada noche mi dieta".

Aunque poco cortés, una respuesta adecuada a esta cobardía consistiría en replicar: "No, yo no lo sé de la misma manera que usted". En efecto, la oración "usted sabe, de la misma manera que yo", al borrar la asimetría entre el observador externo y el agente, hace que el punto de vista de la tercera persona conquiste al de la primera y lo elimine en tanto tal. Por esta vía, el agente lleva a cabo una huida de su ser agente responsable. Así, procura borrar la realidad normativa que él también, inevitablemente, es.

Ésta es la arrogancia empírica que a menudo opera de manera tan eficaz como excusa para ese hacer que consiste en "no hacer nada". En esta intervención arrogante del punto de vista de la tercera persona, para el agente, su decisión se convierte en un acto por completo independiente de él; como si su decisión no fuese un resultado de su agencia, sino un dato empírico más que un observador externo podría comprobar.

$\mathrm{Al}$ respecto, recordemos una vez más que el punto de vista de la tercera persona es una construcción auxiliar de la primera persona. Sin embargo, al mismo tiempo no hay que dejar de considerar que las relaciones entre los puntos de vista de la primera y de la tercera persona son, como la mayoría de las relaciones entre las personas, conflictivas, e impregnadas por una razón arrogante que conquista oscilando entre la sofocación y el sabotaje. Me demoraré un poco en estos dos tipos de acción.

Si espontáneamente me dejo llevar por el punto de vista de la primera persona -de mis creencias, deseos, emociones, esperanzas... operando en tanto razones-, este punto de vista tiende a sofocar cualquier otro punto de vista, en particular, el punto de vista de la tercera persona.

La palabra "sofocar" significa, literalmente, "ahogar", "impedir que el otro respire". En general la usamos para hacer referencia a cierta opresión, acoso, un no tener en cuenta a las otras personas, incluso hasta llegar, de algún modo, a "aplastarlas". Cuando el punto de vista de la primera persona sofoca al de la tercera, como se dice, se confunden los propios deseos, creencias, emociones, esperanzas, razones... con la realidad, y se intenta imponerlos, contra viento y marea. Ello sucede a menudo en las relaciones estrechas entre los individuos. No pocas veces, por ejemplo, si se escuchan por separado los relatos de dos personas acerca de su relación de pareja, y sus expectativas, surge la molesta sospecha de que, por lo menos, una de las dos personas sofoca, a la vez, a su punto de vista de la tercera persona, y a la segunda persona efectiva que tiene enfrente; como consecuencia, se sustituye al otro por los propios proyectos y fantasías. Por eso, cuando estimamos a ambas personas, esa sospecha se convierte en dolorosa inquietud; tememos muy pronto encontrarnos frente a una situación similar a la de dos trenes a punto 
de chocar, y descarrilarse, sin que tal vez, ninguna de las dos personas tenga de ello, por el momento, un presentimiento más o menos claro.

Otros ejemplos, muy diferentes y socialmente más peligrosos de sofocar el punto de vista de la tercera persona, los encontramos en cualquier fanatismo (religioso, político, etcétera).

La acción de conquistar sofocando es, en varios sentidos, inmediata y abierta, una consecuencia, a menudo brusca, de la dinámica de la espontaneidad de una primera persona, de sus deseos en expansión, sin autocontroles. Por el contrario, conquistar saboteando consiste en un conjunto de actividades, a la vez, cuidadosamente calculadas y con disimulo, para imponer ciertas aspiraciones. Así, se impide o se entorpece de manera intencional un curso de acción, pero, por miedo a las represalias o para lograr mayor efectividad, se procura ocultar estas maniobras, embozarlas. Por ejemplo, usamos la palabra "sabotaje" cuando a escondidas, los obreros destruyen las herramientas de un taller con el propósito de hacer cumplir ciertas exigencias de mejora.

Sin duda, en no pocas circunstancias, el punto de vista de la tercera persona procura y, a menudo, con eficacia sabotea al punto de vista de la primera persona. He aquí un paciente, que antes de decidirse por un tratamiento riesgoso, consulta dos médicos. No conforme todavía, pide un tercer diagnóstico, un cuarto, un quinto..., un décimo. ¿Cuántos diagnósticos más debe razonablemente pedir este paciente para comenzar a tratarse? Atiéndase que mientras el paciente hace sus sucesivos estudios, la enfermedad, de seguro, empeora. Sin duda, llegado un momento, proseguir consultando al punto de vista de la tercera persona para decidirse - en este caso, continuar acumulando diagnósticos-, sabotea el propósito mismo de la acción que se busca realizar-que en relación con el paciente es curarse.

Ésta es una experiencia común, y suele impedir llevar a término las acciones más variopintas de la vida, desde la compra de una corbata o de un sillón, al diseño del programa económico del combate contra la pobreza en un país. La lección es general: llegado cierto punto, el ejercicio del punto de vista de la tercera persona se vuelve disfuncional respecto de la práctica, y hasta nítidamente pernicioso.

Sin embargo, a menudo los sabotajes del punto de vista de la tercera persona pueden resultar teóricamente mucho más abarcadores y destructivos. En los ejemplos anteriores se consideraron sabotajes particulares del punto de vista de una tercera persona a ejercicios puntuales de la primera persona. No obstante, también existen sabotajes generales teóricos que procuran, en último término, eliminar el punto de vista de la primera persona en tanto tal y, en consecuencia, toda perspectiva. Su propósito es ir "a las cosas mismas", sin valorar; o describir "el mundo tal como realmente es", por ejemplo, llevar 
a cabo una descripción de lo que hay otorgando exclusividad al vocabulario de la física y/o de la química.

Con su patetismo habitual, J. P. Sartre advertía, no hace tanto tiempo (aunque ya parece la prehistoria), que el punto de vista del agente resulta inevitable, que estamos "condenados a la libertad", una frase que en América Latina conmovió a mi generación. De seguro, esa "condena" está ahí. Eliminar de nuestros puntos de vista a la primera persona en tanto agente no es una opción, sino la fantasía para tapar algún fracaso. No obstante, también estamos no menos "condenados" a una realidad empírica que incluye las resistencias de mi cuerpo entre otros cuerpos de la naturaleza, y de mi historia construyéndose en el juego de resistencias con otras historias. Sí, también estamos "condenados" - se podría agregar con patetismo análogo e igual verdad-a las resistencias del mundo.

\section{IV}

Daré todavía un apresurado tercer salto en torno a esas resistencias, o más precisamente, a una de sus - ¿equivocadas?- maneras de incluirlas en ciertos procedimientos de intervenir en el acontecer social y, sobre todo, de explicarlo. Busco, aunque no sea más que vagamente, aludir a esa tendencia que conforma tanto una patología de la tradición de la confianza en la agencia humana, como - ¿paradojalmente?- de la tradición que la amenaza. Me refiero a las culturas de la conspiración, en su doble vertiente: las conspiraciones efectivas o sus intentos, y las teorías de la conspiración.

Usamos la palabra "conspirar" para hacer referencia al acuerdo entre dos o más personas para cometer un acto oculto que dañe a un tercero. Este verbo -que abarca desde el vasto complot a la intriga momentánea- se ha convertido en un fetiche de invocación reiterada en las llamadas "sociedades posmodernas". No se necesita más que abrir un diario o prender un momento la televisión para comprobarlo. Hasta resulta difícil ya imaginar un noticiero o una narración, real o ficticia, sin alguna conspiración, real o postulada. La presunción en favor de la conspiración como modo de actuar y, en particular, como explicación, se ha convertido en un hábito que nos caracteriza.

Quizá no debería sorprender que la tradición de la confianza en las capacidades de la primera persona a menudo recurra a teorías de la conspiración. Basta enfrentarnos a una desigualdad muy grande en la condición social -económica, política...- de los agentes para ejercer su capacidad de acción y ya tenemos, muchas veces no sin razón, conspiradores en la puerta. En efecto, las teorías tradicionales de la conspiración se introducen para explicar -por ejemplo, de vez en cuando muy razonablemente en América Latina- la 
total impotencia de la primera persona de un amplio plural, un "nosotros" amenazado -el pueblo, una clase social, ciertas instituciones...-, por la política de sofocación de una primera persona del singular o de cierto plural muy restringido, un agente todopoderoso y siniestro - un dictador sanguinario, una vasta empresa trasnacional, una ciega burocracia... Frente a estas acciones, parecería que no queda otro recurso que el conspirador y sus sabotajes. (De lejos, los dioses de la tragedia griega, eno son un poco las proyecciones de estos humanos, demasiado humanos conspiradores que, alternativamente, sofocan y sabotean?)

Sin embargo, en tiempos recientes, las explicaciones conspirativas se han apoderado también de las tradiciones opuestas, las tradiciones que, en alguna medida, amenazan o desafian la agencia. Estas tradiciones amenazadoras -en su cuarta versión, la proveniente de las ciencias sociales-, al comienzo enérgicamente rechazaron este tipo de explicaciones. Con esa negativa se procuraba no sucumbir en un vértigo simplificador que sobrevaloraba hasta el delirio la posibilidad de los agentes de sofocar y sabotear a los otros agentes, y desconocía las resistencias tanto negativas, limitadoras, como positivas, constituyentes, de las estructuras económicas, políticas y sociales.

Sin embargo, esta negativa ha ido cayendo en el descrédito con la introducción progresiva en la investigación social de puntos de vista de la primera persona, y el consecuente declive de un dominante punto de vista de la tercera persona modelado -o con aspiraciones de ser modelado- a partir de los patrones de investigación de las ciencias naturales.

Así, a los diferentes tipos enlistados de amenazas en torno a la agencia humana, se les suele agregar ahora una atmósfera resultado de la cultura conspirativa, que empieza por ser su marco para acabar muy pronto por convertirse en su sustancia. Consecuencia: el posible desasosiego frente a la vida social deja paso a un razonamiento arrogante que no conoce otra tarea que la de hilvanar certezas o, más bien, ilusiones de certeza, y no hay ya nada más que explorar.

Sí, en los días que corren la mayoría de nosotros tiende a no quedarse perplejo o dudar en serio ante casi ningún acontecimiento político, económico, o siquiera cultural, por complejo y novedoso que parezca ser, pues tenemos a la mano alguna teoría de la conspiración para explicarlo. Precisamente, las teorías de la conspiración poseen la dudosa virtud -en realidad, un grave vicio- de poder explicarlo todo, incluyendo los contraejemplos más recalcitrantes, aunque para ello tengan que combinar prejuicios más arraigados con la ciencia-ficción más salvaje.

Abandono ya, sin discutir como se merece, este muy resbaladizo ejemplo de la cultura conspirativa, y regreso a la preocupación generadora de esta reflexión: las luchas entre el pensamiento crítico versus la razón arrogante. 
Sospecho que frente a la mayoría de los problemas, prácticos y teóricos, nimios o muy importantes, topamos con inquietudes en algún sentido análogas a este tironeo entre dos tradiciones de pensamiento: aquellas que parten de la confianza en las capacidades humanas, desde el punto de vista de la primera persona, y las otras que se generan en sus muy diversos desafíos, desde el punto de vista de la tercera persona. Por desgracia, ante cualquier dificultad tendemos a suprimir las tensiones, y a abrazarnos de lleno a la razón que sigue la regla de la repetición incesante:

\section{Siempre es bueno más de lo mismo.}

Esta disposición a la desmesura que comparten acciones tan diferentes como las que aconsejan el nacionalismo, el maltrato a las mujeres, la caza de inmigrantes, la debilidad de la voluntad frente a los quesos, el otorgarle exclusividad al vocabulario de la física y/o de la química y las culturas conspirativas, se nutre, entre muchos alimentos más turbios y, de seguro, más perversos, de un olvido elementalísimo: cada vez que se atiende en una dirección se desatiende a las otras. Que es una manera de describir psicológicamente lo que en lógica se conoce como la falacia parte-todo.

Supongamos que un pensamiento crítico que haya recogido algunas lecciones del pensamiento modesto -indudablemente presente en fragmentos de ambas tradiciones-, o para volver a usar la venerable palabra, supongamos que en la filosofía o, al menos, en algunas de sus prácticas, se rehuye abandonar la vocación con que nació, y que no han dejado de presidir sus logros de mayor excelencia. Se procurará, de este modo, retener cierta mirada persistente y, a la vez, móvil, porque se sabe que muchas veces para librarse de un enredo hay que, ante todo, cambiar ligeramente de perspectiva. E incluso en no pocas situaciones se necesita explorar la perspectiva opuesta o saltar a ejemplos por completo diferentes. Un pensamiento hondamente crítico necesita proseguir, pues, distinguiendo y relacionando con constancia y fervor, aunque con frecuencia sin ir paso a paso.

Continuemos suponiendo que esa virtuosa educación de la capacidad de juicio no se deja sofocar ni por las conquistas del momento (en la Academia, pero sobre todo fuera de ella), ni por la propia impotencia y sus desganos. Entonces, sin duda comprobaremos que, en efecto, al menos parte de la labor de la filosofía consiste en combatir las intervenciones, abiertas o encubiertas, de la razón arrogante y sus desmesurados intentos de dominio. Éstos resultan muy variados porque dependen de cada sociedad, de cada tradición, de cada época, de cada lugar, de cada persona, de cada problema, desde los 
más abstractos y teóricos a los más concretos y urgentes. Sin embargo, el hábito de atender y razonar desmesuradamente parciales o, en el extremo, de convertir el desprecio y hasta el mero desdén en "herramienta de análisis", es recurrente.

No se olvide: la razón arrogante es una peste -a menudo al borde de volverse una epidemia práctica o teórica, o ambas- que a cada paso acecha todas las empresas, las más rutinarias y las más inventivas. 